This journal is the official publication of Bangladesh Society of Physiologists (BSP)

Web URL: www.banglajol.info/index.php/JBSP

Abstracted/indexed in Index Copernicus, Director of Open Access Journal, HINARI Index Medicus for South East Asia Region, Google Scholar, 12OR, infobse index, Open J gate, Cite factor, Scientific indexing services

pISSN-1983-1213; e-ISSN-2219-7508

\title{
Article
}

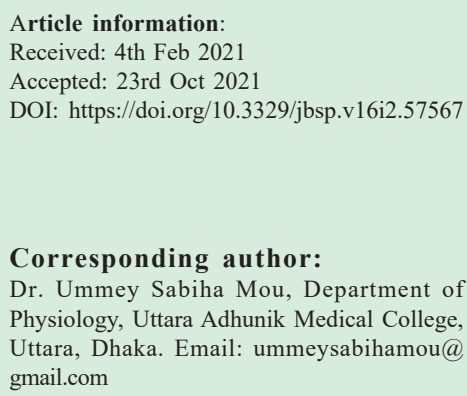

This article is open access licensed under CC BY NC SA which allows readers copy, distribute, display, and perform the work and make derivative works based on it only for noncommercial purposes.

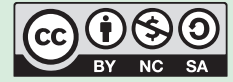

\section{Coagulation disorder in newly diagnosed Overt Hypothyroid patients}

\author{
Ummey Sabiha Mou', Qazi Shamima Akhter ${ }^{2}$ \\ 1. Department of Physiology, Uttara Adhunik Medical College, Uttara, \\ Dhaka \\ 2. Department of Physiology, Dhaka Medical College
}

\section{Abstract}

Background: Various abnormalities of coagulation have been reported in patients with overt hypothyroidism. The coagulation abnormalities may result in mild bleeding tendency to profuse bleeding after any trauma or surgery in overt hypothyroid patients. Objective: To assess the coagulability status in overt hypothyroid patients by estimation of plasma factor VIII level and total count of platelets. Methods: This cross sectional study was conducted in the Department of Physiology, Dhaka Medical College, Dhaka from January 2016 to December 2016. Twenty overt hypothyroid patients with age ranging from 18 to 55 years were selected as study group and twenty healthy subjects were considered as control group. Patients were selected from Outpatients Department of Endocrinology and Nuclear Medicine \& Allied Sciences of Dhaka Medical College Hospital, Dhaka. For assessment of coagulability state, plasma factor VIII level and total counts of platelet were estimated by automated analyzer. For statistical analysis unpaired Student ' $t$ ' test, Chi square test were used. Results: Total count of platelet and plasma factor VIII level were significantly lower $(\mathrm{P}<0.001)$ in overt hypothyroid patients. Conclusion: This study concluded that overt hypothyroid was associated with hypocoagulability and therefore these patients are at higher risk of bleeding tendency.

Keywords: Overt hypothyroidism, Hypocoagulability, Plasma factor VIII level, Total counts of platelet, Bleeding tendency. 
Introduction

H

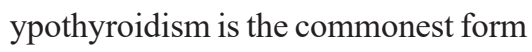
of thyroid disorder. It affects people all over the world of every age, sex, race and level of wealth and education. ${ }^{1}$ Overt hypothyroid patients were defined as grossly elevated thyroid stimulating hormone (TSH) (TSH $>20 \mathrm{mlIU} / \mathrm{L}$ ) level with low $\mathrm{FT}_{4}$ and $\mathrm{FT}_{3}$ levels with clinical sign and symptoms of hypothyroidism.

Thyroid related diseases are common in our country. In 1993, a survey on iodine deficiency disorder in Bangladesh reported goiter in 47.1\% of population and nearly $69 \%$ of Bangladeshi population have shown biochemical evidence of iodine deficiency. ${ }^{2}$ The next national iodine deficiency disorder survey was conducted in 2011 and they reported $6.2 \%$ total goiter rate in that year in rural area. The prevalence of iodine deficiency in children was $33.8 \%{ }^{3}$

Hypothyroidism, if left untreated can lead to many complications. ${ }^{4}$ Low thyroid hormone prevents blood clotting and causes heavy menstrual bleeding in women. Both heavy periods and lower production of blood cells cause anemia. Besides heavy periods, women with untreated hypothyroidism may have amenorrhea or oligomenorrhea. ${ }^{5}$

Various abnormalities of coagulation have been reported in patients with overt hypothyroidism. These abnormalities involve primary and, secondary hemostasis and fibrinolysis. The disorders of coagulation and fibrinolysis usually range from subclinical laboratory abnormalities to life-threatening hemorrhages and thrombotic events depending on the severity of the disease. ${ }^{6-}$ ${ }^{7}$ The coagulation abnormalities in patients with thyroid hormone deficiency results in a bleeding tendency that is usually mild e.g. nose or gingival bleeding, menorrhagia, easy bruising but which can, rarely, be severe e.g. hemorrhages following trauma or surgery. ${ }^{8}$

Platelets are major elements of primary hemostasis and endothelial repair. Platelet size, shape and number are the determinant of platelet function. Several studies have been reported significant decrease in platelet count in hypothyroid patients. ${ }^{9,10}$ Numerous studies have reported that patients with overt hypothyroidism is associated with a bleeding tendency as reflected by decreased level of factor VIII and vWF.

Different researchers and organizations of different countries performed study on platelet count and factor VIII level in overt hypothyroid patients. The gravity of this issue in Bangladeshi population is not yet known as there are less published data regarding this topic in country. The present study aimed to estimate the total platelet count and plasma factor VIII levels to assess the coagulation status in overt hypothyroid patients in Bangladesh.

\section{Methods}

This cross sectional study was conducted in the Department of Physiology, Dhaka Medical College (DMC), Dhaka, from January to December 2016. Ethical permission was taken from Ethical Review Committee of Dhaka Medical College. Twenty newly diagnosed overt hypothyroid patients aged 18-55 of both sexes based on laboratory value of serum $\mathrm{FT}_{3}, \mathrm{FT}_{4}$ and $\mathrm{TSH}$ levels were enrolled from Outpatients Department of Endocrinology and Nuclear Medicine \& Allied Sciences of Dhaka Medical College Hospital, Dhaka. Twenty healthy subjects with similar age and sex were selected as controls on the basis of normal serum $\mathrm{FT}_{3}, \mathrm{FT}_{4}$ and $\mathrm{TSH}$ levels. All the subjects were free from other co-morbid condition such as diabetes mellitus, hypertension, heart, liver and kidney diseases, blood coagulation disorder, sever infection, stroke. After the selection of the subjects, the nature, purpose and benefit of the study were explained to each subject in details and informed written consent was taken. Before taking blood, detailed family and medical history were taken. Anthropometric measurement of the subjects

Volume 16 No. 2 December 2021: 77-81 
was done. All the information was recorded in a data schedule. With aseptic precaution, $5 \mathrm{ml}$ of venous blood were collected from ante-cubital vein by $10 \mathrm{cc}$ disposable plastic syringe from each subject after an overnight fast (at least 12 hours). From the collected blood, $2 \mathrm{ml}$ of blood was transferred to an EDTA containing tube for platelet count and $3 \mathrm{ml}$ blood was taken in another tube containing $3.2 \%$ sodium citrate for the estimation of plasma factor VIII level. Then the sample was taken to the Department of Hematology, DMCH. Platelet count was estimated by Sysmex Automated Hematology Analyzer [XT2000i/ XT- 1800i], Sysmex Corporation, KOBE, Japan and manual checking. Plasma factor VIII level was analyzed on automated coagulation analyzer, Sysmex CA - 500 series by 1-Stage APTT-Based Factor Assays. All the parameters were expressed as mean $\pm \mathrm{SD}$ (standard deviation). Unpaired Student's ' $t$ ' test was done to compare between the groups and chi-square test was performed to compare male and female between the groups. p value $<0.05$ was accepted as level of significance. Statistical analyses were performed byusing a computer based statistical program SPSS (Statistical package forsocial science) Version 22.0.

\section{Results}

In this study no statistical differences were observed in age, sex, BMI, systolic blood pressure (Table I). In this study, mean platelet count and plasma factor VIII level were significantly lower in patients with overt hypothyroidism than controls (Table II).

Table I: General characteristics of the subjects in both groups $(\mathrm{N}=40)$

\begin{tabular}{lccc}
\hline Parameters & Control $(\mathrm{n}=20)$ & Overt hypothyroid $(\mathrm{n}=20)$ & $\mathrm{p}$ value \\
\hline Age $($ years $)$ & $34.95 \pm 10.4$ & $30.95 \pm 7.41$ & $>0.05$ \\
${ }^{\text {Male }}$ & $4(20.0)$ & $4(20.0)$ & $>0.05$ \\
Female & $16(80.0)$ & $16(80.0)$ & $>0.05$ \\
Height $(\mathrm{cm})$ & $159.10 \pm 7.31$ & $158.50 \pm 8.53$ & $>0.05$ \\
Weight $(\mathrm{kg})$ & $56.20 \pm 7.58$ & $56.40 \pm 11.40$ & $>0.05$ \\
BMI $\left(\mathrm{kg} / \mathrm{m}^{2}\right)$ & $22.15 \pm 1.23$ & $22.45 \pm 3.35$ & $>0.05$ \\
Systolic BP $(\mathrm{mmHg})$ & $115.25 \pm 7.34$ & $121.25 \pm 6.46$ & $>0.05$ \\
\hline
\end{tabular}

Results were expressed as mean \pm SD. The test of significance was calculated and $\mathrm{p}$ value $<0.05$ was accepted as level of significance. Unpaired Student's ' $t$ ' test was performed to compare between groups, \# = Chi square test was performed to compare male and female. $\mathrm{N}=$ total number of subjects, $\mathrm{n}=$ number of subjects in each group, $\mathrm{BMI}=$ Body mass index.

Table II: Platelet count and Plasma factor VIII level of the subjects in both groups $(\mathrm{N}=40)$

\begin{tabular}{lccc}
\hline Parameters & Control $(\mathrm{n}=20)$ & Overt hypothyroid $(\mathrm{n}=20)$ & $\mathrm{p}$ value \\
\hline Platelet count $\left(\times 10^{3} / \mu \mathrm{L}\right)$ & $268.75 \pm 42.10$ & $169.30 \pm 35.74$ & $<0.001^{* * *}$ \\
Plasma Factor VIII $(\%)$ & $121.32 \pm 14.96$ & $73.15 \pm 27.51$ & $<0.001^{* * *}$ \\
\hline
\end{tabular}

Results were expressed as mean $\pm \mathrm{SD}$. Unpaired Student ' $\mathrm{t}$ ' test was performed to compare between groups, $\mathrm{N}$

$=$ total number of subject. $\mathrm{n}=$ number of subjects, ${ }^{* * *} \mathrm{P}<0.001$

Volume 16 No. 2 December 2021: 77-81 
Discussion

In the present study, mean platelet count and plasma factor VIII level were lower in patients with overt hypothyroidism than that of controls. This result is similar to others. ${ }^{9-12}$ Several studies have reported the presence of platelet-associated IgG (PAIgG) and circulating platelet auto antibodies in hypothyroid patients. These autoantibodies bind to platelet antigens and cause its premature destruction by the reticuloendothelial system leading to thrombocytopenia. ${ }^{13-14}$ In hypothyroid patients, there is relatively more fat content than cell content in bone marrow. Their marrow space contains an excess of hyperemic or edematous non hematopoietic tissue causing the marrow is extremely hypocellular and fatty. Therefore, megakaryocytopoiesis may be severely inhibited in hypothyroid patients and cause decreased platelet count. ${ }^{15}$ Thyroid hormone stimulates the breakdown of mucopolysaccharides to soluble and excretable molecular size. This rate of breakdown is decreased in hypothyroid patients which may result in an increased accumulation of these substances in the connective tissue of bone marrow. Replacement of marrow ground substance by these hyaluronic acid-rich mucopolysaccharides causes decreased marrow stem-cell proliferative capacity leading to decrease in platelet count in hypothyroid patients. ${ }^{16}$ Some studies reported decreased plasma factor VIII levels in hypothyroid patients which might be due to generalized decrease in protein synthesis. ${ }^{17}$ In hypothyroidism, there is a decreased amount of mRNA specific for factor VIII components which leads to a decreased synthesis of factor VIII molecule from hepatocytes and endothelium. ${ }^{18,19}$

\section{Conclusion}

From the results of the study, it can be concluded that hypocoagulability was associated with overt hypothyroid patients. Therefore, estimation of platelet and factor VIII might be helpful for prediction of future risk of bleeding tendency in hypothyroid patients.

\section{Conflict of Interest None}

\section{Acknowledgement}

The authors acknowledge the Department of Hematology, DMCH, Dhaka, for their kind cooperation to carry out the laboratory investigations.

\section{References}

1. ATA. Hypothyroidism: A Booklet for Patients and Their Families [Internet]. USA. American Thyroid Association. C2013. [cited 2016, may 26]. Available from: www.thyroid.org.

2. Yusuf H K M, Quazi S, Kahn M R, Mohiduzzaman M, Nahar B, Rahman M M, Khan M A, Shahidullah M, Hoque T, B aquer M, Pandav CS. Iodine deficiency disorders in Bangladesh. Indian J Pediatr 1996; 63 (1): 105-10.

3. Tiny amounts of iodine can prevent IDD. Bangladesh Sangbad Sangstha (BSS). 2015 May 3: [Cited 2016 Sep 21]; Letters: [about 2p]. Available from: www.bssnews.net/news Details.php?cat $=0 \& \mathrm{id}=489662 \$$.

4. Dadi S. Thyroid and its Complications. RRJMHS. 2015 May-June; 4 (3). Available from: www.rroij, com/opcu-access/thyroid-and-itscomplications php?aid $=52799$.

5. Collins S. Women's Health. [Internet]. c2014. What hypothyroidism Can Do to Your Body; 2015 Dec 29 [cited 2016 Aug 5]. Available from: www.webmd.com/women/features/low-thyroidcomplications.

6. Franchini M, Lippi G, Manzato F, Vescovi P P, Tergher G. Hemostatic abnormalities in endocrine and metabolic disorder. Eur J Endocrinol 2010; 162: 439-51.

7. Chadarevian R, Bruckert E, Leenhardt L, Giral P, Ankri A, Turpin G. Components of the Fibrinolytic System Are Differently Altered in Moderate and Severe Hypothyroidism. J Clin Endocrinol Metab 2001; 86 (2): 732-37.

8. Franchini M. Haemostasis and thyroid diseases revisited. J Endocrinol Invest. 2004; 27(9): 88692.

Volume 16 No. 2 December 2021: 77-81 
9. Gullu S, Sav H, Kamel N. Effect of levothyroxine treatment on biochemical and hemostasis parameters in patients with hypothyroidism. Eur J Endocrinol 2005; 152: 355- 61 .

10. Mohamed-Ali M S, Ahmed R O. Coagulation profiles in hypothyroid and hyperthyroid female patients in Sudan. Saudi Med J 2008; 29(9): 128993.

11. Erem C, Ucuncu O, Yilmaz M, Kocak M, Nuhoglu I, Ersoz H O. Increased thrombin-activatable fibrinolysis inhibitor and decreased tissue factor pathway inhibitor in patients with hypothyroidism. Endocrinol 2009; 35: 75-80.

12. Homoncik M, Gessl A, Ferlitsch A, Jilma B, Vierhapper H. Altered Platelet Plug Formation in Hyperthyroidism and Hypothyroidism. J Clin Endocrinol Metab 2007; 92(8): 3006-12.

13. Bowles K M, Turner G E, Wimperis J Z. Resolution of chronic severe refractory thrombocytopenia after treatment of hypothyroidism. J Clin Pathol 2004; 57: 995-96

14. Cordiano I, Betterle C, Spadaccino C A, Soini B, Girolami A, Fabris F. Autoimmune thrombo- cytopenia (AITP) and thyroid autoimmune disease (TAD): overlapping syndromes? Clin ExpImmunol 1998; 113: 373-78.

15. Axelrod A R, Berman L. The Bone Marrow in Hyperthyroidism and Hypothyroidism. Blood 1951; 6: 436-53.

16. Savage R A, Sipple C. Marrow Myxedema. Gelatinous Transformation of Marrow Ground Substance in a Patient with Severe Hypothyroidism. Arch Pathol Lab Med 1987; 111(4): 375-7.

17. Crispell K R, Parson W, Hollifield G. A study of the rate of protein synthesis before and during the administration of L-triiodothyronine to patients with myxedema and healthy volunteers using N-15 glycine. J Clin Invest 1956; 35(2): 164-69.

18. Blessing N E, Hambley H, McDonald G A. Acquired von Willebrand's disease and hypothyroidism: report of a case presenting with menorrhagia. Postgrad Med J 1990; 66: 474-76.

19. Graninger W, Pirich K R, Speiser W, Deutsch E, Waldhausl W K. Effect of Thyroid Hormones on Plasma Protein Concentration in Man. J Clin Endocrinol Metab 1985; 63(2): 407. 